$$
\begin{gathered}
\text { ELEXACERBADO } \\
\text { BELICISMO DEL HIMNO } \\
\text { NACIONAL MEXICANO } \\
\text { COMO INCONGRUENCIA } \\
\text { GNOSEOLOGICA } \\
\text { EN UNA SOCIEDAD } \\
\text { QUE INTENTA CONSTRUIR } \\
\text { UNA CULTURA DE PAZ }
\end{gathered}
$$





\title{
El exacerbado belicismo del Himno Nacional Mexicano como incongruencia gnoseológica en una sociedad que intenta construir una cultura de paz
}

\author{
Saúl Adolfo Lamas Meza \\ Universidad Tecnológica de Guadalajara \\ https://orcid.org/0000-0002-4680-9513 \\ slamas100@hotmail.com
}

\section{Introducción}

El presente trabajo tiene como finalidad desarrollar un análisis hermenéutico de la letra del himno nacional mexicano, a efecto de profundizar en su metalenguaje beligerante. A través de glosas contextuales, se analiza meticulosamente el alcance alegórico de sus frases, con el objetivo de evidenciar la violencia explícita, el lenguaje machista y el talante bélico del que está permeado. A través de ejemplificaciones puntuales de la realidad presente, se da cuenta de la incidencia que el himno tiene en la conducta cotidiana e idiosincrasia del mexicano. Finalmente, a través de un análisis sistemático, se valora si es necesario modernizar la letra del himno, con la intención de promover una ideología renovada que permita proscribir la violencia social, fomentar la justicia restaurativa e incentivar la cultura de paz.

Cada país del mundo tiene su propio himno nacional, cuya letra musicalizada narra la idiosincrasia, cultura, historia, creencias, tradiciones, hazañas y aspiraciones de esa nación. Los ciudadanos sienten un gran orgullo al entonar su himno, mientras llevan la mano a su corazón, expresando con ello veneración, amor y gratitud por su tierra, la cual es el origen de su vida y el espacio geográfico sagrado en el que se desenvuelve su destino.

En México, el himno nacional es considerado un símbolo patrio - junto con el escudo y la bandera-, el cual debe ser cantado con total solemnidad y respeto. Cualquier alteración a la letra, manipulación de su patrón sonoro o utilización inapropiada, es sancionada por las autoridades. La Ley sobre el Escudo, la Bandera y el Himno Nacional, establece taxativamente los parámetros para su utilización. En justas deportivas, eventos académicos, culturales, cívicos y protocolarios oficiales, el himno se canta con supina altivez por niños, jóvenes, adultos y ancianos que repiten ufanos su estribillo y estrofas. Letra a pesar de su estilo barroco y abstruso, es absorbida por el subconsciente de quienes escuchan y entonan sus frases líricas. 
Escrita en un contexto de posguerra, la letra redactada por el poeta potosino, Francisco González Bocanegra, narra las épicas hazañas de los guerreros mexicanos en su prolongada lucha de emancipación reivindicatoria. Una historia plasmada de esperanza sempiterna, verde como sus inconmensurables praderas veraniegas, prístinas y transparentes como el blanco sueño de sus niños y roja como sus campos de guerra, teñidos de muerte. Originalmente, el himno estuvo compuesto de un estribillo y diez estrofas, las cuales han sufrido cambios en el devenir del tiempo, siendo adaptadas a ciertos contextos históricos coyunturales.

A más de un siglo y medio de su promulgación original, en todas las latitudes del país se sigue entonando su letra, que atisba a un pasado que nos parece ya lejano. En el presente ensayo, a través de un análisis sistemático y hermenéutico de su letra completa, profundizaremos en sus metáforas, para explicar, a través de glosas, su metalenguaje, sus sonidos explícitos y sus implícitos silencios.

\section{Análisis hermenéutico de la letra del himno nacional mexicano}

"Mexicanos al grito de guerra". Esta primera frase inicia con el gentilicio "mexicanos" y aunque su empleo pluralizado es correcto, se puede advertir un sesgo machista, ya que el himno en reiteradas ocasiones hace alusión al hombre y solo en una ocasión a la mujer. El otrora presidente Vicente Fox, en sus discursos públicos, refiriéndose al pueblo en abstracto, popularizó la frase "mexicanos y mexicanas", explicando que esta expresión era más incluyente y que pretendía mostrar un trato de igualdad ontológica para todos: mujeres y hombres, sin exclusión. La Constitución Política de los Estados Unidos Mexicanos en su numeral cuarto establece: "la mujer y el hombre son iguales ante la ley".

Llama la atención que en esta frase del himno se utilice la palabra "grito", lo cual denota agresividad explícita, ya que bien podría haberse utilizado el vocablo "llamado"—al llamado de guerra-, pero se optó por emplear un término de hostilidad e intimidación. El hecho de "gritar", tiene muchas implicaciones a nivel psicológico, primero hace alusión a la acción de aumentar los decibeles de la voz, con la intención de forzar la escucha del interlocutor que no oye o no que quiere oír, cuando se le habla con un timbre moderado.

En la psicología del mexicano está muy arraigada la sensación de impotencia y frustración, a raíz de la colonización y ultraje que sufrieron sus pueblos prehispánicos, debido a la conquista con la que los europeos silenciaron su cultura, a través de una transculturación forzada, en la que se impuso una nueva religión, un nuevo idioma, una nueva ideología; dejando con ello un trauma taciturno en su subconsciente colectivo. "La caída de Quetzalcóatl en su más profunda significación" (Aceves, 1991, p. 104). A partir de ahí, en la memoria del mexicano, hay una necesidad de expresar un grito estridente de liberación psicológica, un 
grito estentóreo de dolor que clama venganza, emancipación y reivindicación. El grito como respuesta reactiva a un período prolongado de silencio contenido.

Por otra parte, "gritar" representa la tentativa de imponerse sobre el otro, anulándole a través de una actitud estruendosa y amenazante. Esta conducta es un mecanismo de defensa que ha sido utilizada milenariamente por los miembros del reino animal, que durante la cacería evocan alaridos para detener e intimidar a su presa — el rugido de león, el aullido del lobo, el bramido del jaguar, el ladrido de los perros, etcétera- Bien es sabido que el hecho de levantar la voz para imponer superioridad exógena viene disfrazado de un complejo de inferioridad interno.

El vocablo "guerra", incita inmediatamente a la predisposición para la lucha, para el conflicto. El stress que se genera en el devenir de la "lucha cotidiana", tiene su origen en una sociedad capitalista que fomenta a cada instante la competencia recalcitrante. A los niños desde muy pequeños se les adiestra por sobresalir en las aulas y luchar para obtener las más altas calificaciones, programándoles con la idea de que sólo los mejores serán ganadores en la vida y tendrán acceso a mayores beneficios. El estudiante que no actué así, es considerado un “loser". El egoísmo es acicalado por los profesores, que prohíben categóricamente que un niño comparta sus tareas con sus compañeros, con lo que se acrecienta la rivalidad que se prolonga inclusive en el recreo, donde los niños compiten practicando deportes y ejercicios lúdicos en los que todos quieren ganar y nadie perder. La victoria da honor al vencido y trae ignominia al perdedor.

El sistema educativo prepara a los guerreros del futuro, quienes, uniformados, deben presentarse puntuales todos los días para recibir instrucción de sus superiores, cuya autoridad no puede ponerse jamás en entredicho. El belicismo académico es superlativo. La desobediencia es castigada y la disciplina premiada con insignias, pues no hay mayor honor que llegar a casa con una estrella, no colocada en el uniforme como la reciben los militares, sino adherida en la frente. Los adultos viven lo propio cada día, en la refriega cotidiana, luchando en su jornada de trabajo - la palabra trabajo significa sortear trabas-. El recelo y la competencia entre compañeros crean no pocas veces ambientes laborales de gran tensión. En la oficina, en la obra, en las bodegas o en las fábricas, el mexicano deberá estar siempre al pie del cañón.

El mexicano vive un clima belicista social cotidiano, en el que debe mostrar a cada oportunidad su valía. "Un mexicano es un problema siempre, para otro mexicano y para sí mismo" (Paz, 1984, p.63). En el mundo se sabe que el macho mexicano jamás se rinde, y su valentía la demostrará en cada oportunidad, tanto en la escuela, como en el trabajo e incluso durante la comida - la cual acompaña de mucho picante-, así como en las competencias deportivas de combate corporal; principalmente el taekwondo y el boxeo, disciplinas en las que nuestro país tiene grandes representantes.

"El acero aprestad y el bridón”. Esta frase es muy significativa, "aprestad el acero", alude a empuñar la espada y estar presto para el ataque, con lo cual se 
evidencia un incitamiento explícito a la violencia. En la actualidad muchos delitos como el robo, homicidios, lesiones o agresiones sexuales, se cometen utilizando "armas blancas", es decir, instrumentos con hoja afilada y punta cortante. Cada que el mexicano entona esta frase, en el fuero interno de su subconsciente, su psique recibe un mensaje para la exteriorización de agresividad, mensaje que además se expresa, no de manera sugerente, sino imperativa.

"El bridón”, refiere a la brida que se coloca en el caballo, a manera de rien$\mathrm{da}$, para ensillarlo y prepararlo para iniciar la carrera, lo cual alude a las guerrillas, donde los jinetes montados en sus caballos iniciaban campañas de embestida contra un pueblo o grupo adversario. En la actualidad, ya en ningún enfrentamiento bélico se utiliza la caballería armada, por ser totalmente obsoleta para los fines de una guerra, tomando en cuenta la evolución acelerada que ha tenido la tecnología armamentista en los últimos años. Es menester recordar que el himno fue escrito en 1854, momento histórico que aún venía arrastrando resabios bélicos posteriores a la independencia, debido a revueltas civiles al interior del país y a algunos conflictos externos. Empero, en la jerga popular del mexicano es recurrente escuchar vocablos ecuestres tales como: "ir desbocado", "perder los estribos", "actuar con rienda suelta", "montarse en su macho", "lidiar con alguien”, "hacer desplantes”, "tener carácter de mula”, “ser bronco”, etc. Frases todas que aluden a una actitud de excentricismo u hostilidad.

"Y retiemble en sus centros la tierra". Aquí, en esta frase, se hace alusión al estremecimiento, al movimiento impulsivo y caótico que se produce cuando se inicia el estallido de la guerra. Retemblar en sus centros, implica movilizar el eje de la tierra, una especie de movimiento tectónico que trae la latencia de la devastación. La frase "retemblar su centro", focalizada al individuo, representa movilizarle de su centro, es decir, descentrarle, a través de una trémula polarización.

En México, cuando la tierra tiembla, se activa en la psique del mexicano y en su memoria celular, sensaciones de temor y caos, en razón de la evocación del terrible terremoto que se suscitó en 1985 en el país. El fenómeno trajo gran devastación —edificios caídos, monumentos dañados y múltiples pérdidas humanas- y sin duda quedó grabado por mucho tiempo en la memoria de esta nación. Al ser un país de gran actividad sísmica, el Servicio Sismológico Nacional ha reportado más de 12,000 sismos de diferentes magnitudes en la escala de Richter en el territorio nacional, solamente en el primer semestre del año 2021 (Servicio Sismológico Nacional, 2021). Es por ello que cuando el himno clama: "retiemble en sus centros la tierra", se activa en el mexicano a nivel del subconsciente colectivo una sensación de estrés y zozobra, producto del recuerdo traumático de aquellos terremotos que cimbraron a México hace no muchas décadas.

"Al sonoro rugir del cañón”. Aquí nuevamente se vuelve hacer alusión al sonido iracundo, al bramido colérico de un instrumento bélico de destrucción, capaz de derribar puentes y hacer colapsar fortalezas. Es el animus exacerbado de guerra en su máxima expresión. En México, la ley que regula la utilización de armas para fines de defensa legítima es la Ley Federal de Armas de Fuego y 
Explosivos, la cual establece los parámetros para el registro y portación de armas que los ciudadanos pueden detentar en sus domicilios.

Según el reporte anual de la Secretaría de Seguridad Pública, “en el año 2020 se cometieron 34,515 homicidios dolosos, de los que el $70 \%$ fueron perpetrados con la utilización de armas de fuego" (Arista y Flores, 2021). En México, la proliferación del mercado negro de armas, el aumento de la violencia y la propagación de grupos de delincuencia organizada, han aumentado dramáticamente en las últimas décadas. El "rugido del cañón” es el sonido estridente cuyo eco incisivo se empieza a normalizar en la sociedad mexicana.

"Ciña, joh Patria!, tus sienes de Oliva”. En esta frase se hace evocación a la “patria”, cuya raíz etimológica pater, patris, significa padre; aludiendo al patriarcado y haciéndose referencia a México con un pronombre vocativo masculino. La madre es anulada de la gloria de los olivos, solo el padre es digno de esta gloriosa distinción. “Ceñir las sienes de oliva”, significa poner en la cabeza una aureola diseñada con ramas de olivo, lo que representa al arquetipo del vencedor.

En muchas pinturas y proyecciones cinematográficas es común que tanto al Emperador -César-, como a los grandes conquistadores romanos, se les represente con un ramillete que circunda su cabeza, lo que hace alusión a la insignia de poder y coronación. Honrar a alguien con la corona de olivo, es una práctica cuyo origen se remonta a los antiguos juegos olímpicos, que se practicaban en Grecia. Por lo que es muy común ver esta imagen en algunos pebeteros en las justas olímpicas. En los juegos olímpicos de Atenas, del año 2004, en la ceremonia de premiación a todos los atletas se les puso una corona de olivo en su cabeza, después de recibir su medalla, rememorando con ello las épocas de competencias deportivas que tuvieron verificativo en la antigua ciudad de Olimpia, en Grecia.

"De la paz, el arcángel divino”. Paradójicamente en esta frase se alude a la palabra paz, que queda muy empequeñecida en la letra del himno, tan saturada con lexicología bélica. Sin embargo, en esta frase se hace referencia a que esta paz le pertenece al arcángel divino, no al hombre per se, con lo cual se infiere que el sosiego solo puede ser alcanzado en los planos celestiales, después de la muerte, ya que en vida el humano debe afrontar con estoicismo las tribulaciones de la lucha cotidiana.

La utilización del vocablo arcángel, evidencia la influencia de la religión católica en el pueblo mexicano. Bien es sabido que, en múltiples guerras, los estándares religiosos son utilizados por las tropas como banderas o símbolos que incorporan a sus atuendos. Este personaje alude probablemente al arcángel Miguel, que en el culto católico representa al soldado de Dios, "el príncipe de la milicia celestial”, quien con armadura y espada erguida lucha contra el mal y protege a los humanos de peligros y asechanzas.

"Qué en el cielo tu eterno destino". Esta frase tiene implícito un complejo de superioridad manifiesta. En primer lugar hace alusión a Dios en su aspecto masculino, no a la divinidad en su expresión femenina. El himno asume que Dios 
ha diseñado un destino para este país ya predeterminado, es decir, el sino de ser inevitablemente un pueblo guerrero. Esto trae consigo un gran peso para el pueblo mexicano, condenado sistemática y quizá sempiternamente a la experiencia del conflicto. Evolución y revolución serán dos categorías que estarán correlacionadas de forma ineluctable en el proceso de vida del mexicano. Además, cuando se hace alusión a un "destino en el cielo", se infiere la idea del premio que se alcanzará después de la muerte, en los planos eterios; ideología que es promovida profusamente en múltiples religiones del mundo: el sufrimiento abnegado en la tierra, para después ser merecedor de toda suerte de placeres y recompensas en el cielo.

"Por el dedo de Dios se escribió". Esta frase afirma que el destino del pueblo mexicano fue redactado directamente por el Dios creador y no indirectamente por profetas que recibieron esta información de forma secundaria, como en la cosmogonía de otros pueblos. Esta frase nos recuerda a la pintura que Miguel Ángel plasmó en la bóveda de la Capilla Sixtina, intitulada "La creación de Adán”, en la que se observa la divinidad levitando, mientras extiende su dedo índice hacia la tierra, intentando a su vez hacer contacto con el dedo índice del hombre, el cual yace en el suelo. Algo que se advierte en esta representación es la ausencia de Eva. La mujer de acuerdo al pasaje bíblico del Génesis, fue creada de forma secundaria a través de la costilla del varón.

En lo cotidiano, señalar con el dedo índice tiene la función de mostrar la localización de un objeto o un sujeto, o en su caso, la intención de acusar a alguien. En la cultura popular, apuntar a alguien directamente con el dedo es una actitud que denota falta de respeto y educación, ya que implica denostación. Cuando el dedo índice se muestra de manera vertical al interlocutor, se hace para expresar autoridad, ya que la intención de esta gesticulación es dar una orden o una reprimenda categórica al interpelado. En México, este tipo de lenguaje corporal es muy utilizado y suele acompañarse de una actitud petulante durante el habla cotidiana.

"Mas, si osare un extraño enemigo". Esta frase hace alusión al extranjero y al proscrito, que son vistos como enemigos peligrosos que deben ser segregados; que si tienen la osadía de acercarse a nuestro territorio, se encontrarán entonces con una horda furibunda de mexicanos que les harán ver su suerte. El nacionalismo está tan arraigado en México que muchas expresiones extranjeras son consideradas ultrajes a nuestra patria. El sentido de nacionalismo se ve extrapolado incluso a los estadios de fútbol, como ocurre en los encuentros contra otras selecciones, cuando algunos aficionados profieren insultos explícitos a los jugadores contrincantes. A mediados del 2021, la FIFA -Federación Internacional de Fútbol Asociación- castigó a México con el veto de su estadio, por los reiterados gritos homofóbicos y discriminatorios que la afición emitió en encuentros pasados. ${ }^{1}$ Por otra parte, celebrar las fiestas patrias es un acto de

${ }^{1}$ La situación se agravado al punto que la FIFA, ante la reiterada práctica homofóbica de los aficionados mexicanos en contra de las selecciones nacionales extranjeras, ha emitido 
gran orgullo mexicano, pero cuando este tipo de expresiones se polarizan, al grado de desembocar en actos de hostilidad e intolerancia, es cuando esta práctica se torna tóxica.

"Profanar con su planta tu suelo". Se sabe que el mexicano es un ser territorial por antonomasia, que mira con recelo a aquél que invade su perímetro personal; siendo incluso capaz de agredir a quien irrumpa en sus propiedades. En la sociedad mexicana son muy comunes los pleitos vecinales suscitados por la disputa de cajones de estacionamiento, por la invasión que los ramajes de árboles hacen en la propiedad vecina, por perros que ensucian las banquetas, por niños que juegan y pisan el jardín aledaño, etc. La utilización de letreros amenazantes tales como: "se ponchan llantas", "cuidado con el perro", "vecinos alerta", u otros parecidos, se han popularizado en las fachadas de múltiples hogares.

El mexicano es un ser que mira de soslayo a su vecino, a veces con miedo, a veces con recelo. Para el mexicano, la defensa del territorio, es muy importante. La inviolabilidad del domicilio es un derecho constitucional reconocido en el artículo 16 de la Carta Magna, el cual reza en su primer párrafo:

Nadie puede ser molestado en su persona, familia, domicilio, papeles o posesiones, sino en virtud de mandamiento escrito de la autoridad competente, que funde y motive la causa legal del procedimiento (Constitución Política de los Estados Unidos Mexicanos, 2021, p.17).

La propiedad privada es un bien jurídico tutelado por el derecho constitucional y la vulneración de esta prerrogativa es penalizada, como se desprende del numeral 285 del Código Penal Federal:

Se impondrán de un mes a dos años de prisión y multa de diez a cien pesos, al que, sin motivo justificado, sin orden de autoridad competente y fuera de los casos en que la ley lo permita, se introduzca, furtivamente o con engaño o violencia, o sin permiso de la persona autorizada para darlo, a un departamento, vivienda, aposento o dependencias de una casa habitada (Código Penal Federal, 2021, p.265).

En México es permitida la portación e incluso la utilización de armas de fuego, en el interior del domicilio, si esta es usada para defender el patrimonio o para repeler en legítima defensa una agresión real, actual e inminente, que venga de un enemigo extraño que intente profanar un espacio.

"Piensa, ;Oh Patria querida!, que el cielo un soldado en cada hijo te dio". Esta frase reafirma el juramento a la patria — patriarcado_-, la cual deberá tener la certeza de que en cada mexicano encontrará un guerrero infatigable, dispuesto a defenderle hasta paroxismos insospechados.

un ultimátum, advirtiendo a la Federación Mexicana de Fútbol que en caso de repetirse estas conductas, la selección mexicana será vetada del Mundial de Qatar 2022. 
"; Guerra, guerra, sin tregua al que intente, de la patria manchar los blasones!". En esta frase se utiliza en dos ocasiones el vocablo guerra, reafirmando el talante bélico que acompaña en todo momento — sin tregua- a nuestro himno patrio. El grado de veneración hacia los emblemas patrios, se presenta en esta lírica, como algo de categoría casi inmaculada y divina.

“;Guerra, guerra! Los patrios pendones, en las olas de sangre empapad”. Aquí se advierte una paradoja curiosa, mientras en líneas anteriores se expresaba que se descargaría el furor de la guerra a quien mancillara los blasones -insignias-, en esta frase complementaria de la estrofa, se pide que los pendones -insignias representadas por banderas-, sean empapadas de sangre.

"Guerra, guerra! En el monte, en el valle, los cañones horrísonos truenen y los ecos sonoros resuenen con las voces de ¡Unión!;Libertad!”. La guerra debe expandirse a cada rincón, la estridencia del cañón debe retumbar y replicarse -en ecos- a efecto de alcanzar la unión y la libertad. ¿Hacer la guerra, para conseguir la paz? ¿Destrozar al enemigo para conseguir la unión? ¿Asesinar para alcanzar la libertad? A priori, estas frases contienen crasos errores conceptuales y gnoseológicos.

"Antes, patria, que inermes tus hijos, bajo el yugo su cuello dobleguen, tus campiñas con sangre se rieguen, sobre sangre se estampe su pie”. En esta frase se expresa textualmente que es preferible la muerte antes que la humillación de rendirse en el combate. "Doblegar el cuello", es un acto de cobardía que no puede permitirse bajo ninguna circunstancia, ya que esto representaría una deshonra para la patria, la cual sólo puede admitir que su guerrero perezca en la fragua del combate, pero jamás aceptaría su declinación durante la lucha.

En México, cuando se hacen operativos para capturar a algún líder de una organización criminal, se ha observado que cuando alguno de estos capos se ve acorralado, él y su grupo prefieren batirse en el intercambio de balas, antes de entregarse a las autoridades. Incluso, en algunas ocasiones, se ha documentado que algunos de estos cabecillas han optado por suicidarse, antes que sufrir la vejación de ser aprehendidos.

"Y sus templos, palacios y torres, se derrumben con hórrido estruendo". La postal que se describe en esta estas líneas, no puede ser más tétrica y desoladora, ya que refiere a la devastación brutal que deja la guerra, en la que las construcciones son reducidas al polvo. En la religión católica, que es la que profesa la gran mayoría de los mexicanos, existe una ritual eclesiástico que se practica el primer día de cuaresma, y que corresponde al miércoles de ceniza. En su ritual, el sacerdote marca en la frente a los feligreses con polvo de incienso, mientras les expresa la frase: "polvo eres y en polvo te convertirás", a la que con abnegación los devotos responden: "amén”. Este día es uno de los más concurridos en la iglesia, pues tal rito secular es considerado para muchos casi como una bendición. Ser polvo y regresar al polvo es el destino prefijado que con gallardía el mexicano debe aceptar.

"Y sus ruinas existan diciendo: de mil héroes la patria aqui fue". En esta frase se da más importancia al hecho de morir con heroísmo en el combate, que 
a la pérdida que representa la devastación de monumentos y estructuras arquitectónicas reducidas a polvo por el paso de la guerra.

"Patria, patria, tus hijos te juran, exhalar en tus aras su aliento”. El juramento al padre de dar la vida por él. Ofrendando la vida propia, a cambio de la subsistencia de la nación, que es más gigantesca e importante. En la legislación mexicana hay ciertos actos procesales donde se les toma un juramento a algunos intervinientes del proceso, especialmente a los testigos y peritos, quienes ante la Constitución juran decir la verdad y nada más que la verdad en sus declaraciones. Faltar a ese juramento es un perjurio, que técnicamente es un delito tipificado como falsedad de declaraciones y que es sancionado con pena privativa de libertad.

"Si el clarín con su bélico acento, los convoca a lidiar con valor". Ante el llamado a la guerra, el mexicano debe estar presto, dispuesto para acudir sin dilación a tomar las armas para defender con gallardía a la nación de cualquier peligro exógeno. Cuando, en 1943, se instauró el Servicio Militar Nacional como obligatorio para todo varón mexicano que cumpliera 18 años, los enlistados comenzaron a recibir instrucción militar de orden cerrada, que incluía preparación técnica para el manejo de armas. Sin embargo, esta práctica fue suprimida progresivamente respecto de la instrucción militar, debido al aumento de jóvenes que se inmiscuían en actividades delictivas luego de haber terminado su formación, razón por la cual el Estado consideró que dotarlos de este conocimiento era contraproducente.

"iPara ti, las guirnaldas de oliva! ¡Un recuerdo para ellos de gloria! ¡Un laurel para ti de victoria! ¡Un sepulcro para ellos de honor!” El himno nacional termina haciendo alusión a toda la gloria que merece la patria, la cual debe ser adornada de flores y altares, instando a que siempre que nos refiramos a ella, lo hagamos con exultación de ánimo e hipérbole laudatoria. El soldado mexicano, en cambio, siempre y cuando haya dejado en el campo de batalla su sudor, sus lágrimas, sangre y vida, será acreedor a un digno memorial sepulcral.

\section{Consideraciones finales}

El himno nacional mexicano es sublime como pieza literaria, nadie puede negar que la lírica de su letra ostenta elegancia creativa y grandilocuencia. Se ha dicho inclusive que después de la Marsellesa francesa, el himno nacional mexicano es el más bello poéticamente hablando. El poema escrito por Bocanegra, per se, tiene un gran valor literario. Ello nunca ha estado en entredicho.

La crítica exegética que hemos desarrollado en el presente trabajo no es sobre su forma, sino sobre su fondo, es decir, sobre su agudo talante belicista. Si bien lo anterior se justifica en razón del contexto histórico en el que fue escrito, una época en que las guerrillas posteriores a la independencia -civiles unas, 
exógenas otras - aún atizaban el ánimo combatiente de la patria. El himno nacional desde entonces fue un escrito con un marcado sesgo, que pretendía homenajear al otrora presidente Antonio López de Santa Anna. Personaje que en 1829 ganó la guerra de Tampico, proclamándose a sí mismo, a partir de entonces, como "Alteza Serenísima", por haber desterrado por completo a los europeos invasores. De ahí que la letra del himno versé completamente sobre temas vinculados a conflictos armados.

Mientras otros himnos del mundo describen la belleza de sus países, exaltan la grandeza de su cultura, aluden a sus tradiciones, comparten su mística y valores espirituales que ostentan como nación; el nuestro es monotemático, centrado epistémicamente de forma exclusiva en las aristas de la guerra. Su belicosidad está tan inmersa en la cultura que incluso durante su entonación se saluda a la bandera con un mudra-símbolo - militar, y no llevando la palma al corazón como lo hacen en la gran mayoría de los países. El tema de la guerra no sólo ingresa a los oídos y sale por la boca del mexicano durante su entonación, sino que se reafirma visualmente al saludar militarmente a la bandera, cuando se observa en su escudo a una águila privar de la vida a una serpiente.

En el siglo XXI, bajo un clima coyuntural completamente diverso, en donde la promoción de la paz pretende ser la filosofía y eje total que rija las relaciones entre los países del orbe, en el que México ha ratificado todos los tratados internacionales que versan sobre derechos humanos, en el que se ha transitado hacia la implementación de un sistema penal garantista, en el que se han promulgado múltiples leyes de justicia restaurativa y en el que se ha promovido civil e institucionalmente con denuedo la ideología social de paz, conviene replantearnos si el himno nacional, belicoso y sanguinario, como lo es actualmente, corresponde a los valores de fraternidad, hermandad, cooperación, progreso, avenencia, justicia, igualdad, libertad, integración y unidad, que se pretenden instaurar en un país como el nuestro, tan desgastado por el conflicto, y tan anhelante de armonía y sosiego social. Mientras se replique en aulas, institutos, dependencias, foros y plazas públicas un mensaje tan beligerante como el que consigna nuestro himno, será muy difícil consolidar en México una genuina cultura de paz. 


\section{Referencias}

Aceves, M. (1991). El mexicano: alquimia y mito de una raza. México: Editorial Joaquín Mortiz,

Arista, L. y Flores L. (20 de enero de 2021). México cierra 2020 con 35,515 homicidios, el $70 \%$ con armas de fuego. Expansión política. https://politica. expansion.mx/mexico/2021/01/20/mexico-cierra-con-34-515-homicidiosen-2020-el-70-con-armas-de-fuego

Código Penal Federal (2021). Recuperado de www.diputados.gob.mx/leyesBiblio/ pdf_mov/Codigo_Penal_Federal.pdf

Constitución Política de los Estados Unidos Mexicanos (2021). Recuerdo de www.diputados.gob.mx/leyesBiblio/pdf/CPEUM.pdf

Paz, O. (1984). El laberinto de la soledad. México: Fondo de Cultura Económica.

Servicio Sismológico Nacional (agosto 2021). Resumen mensual de sismicidad. Recuperado de http://www.ssn.unam.mx/sismicidad/resumen-mensual/. 